\title{
Predicted and observed sizes of dystrophin in some patients with gene deletions that disrupt the open reading frame
}

Louise V B Nicholson, Kate M D Bushby, Margaret A Johnson, Johan T den Dunnen, Ieke B Ginjaar, Gert-Jan B van Ommen

\begin{abstract}
Among 85 patients with Duchenne and Becker muscular dystrophy, 29 were found to have mutations which disrupted the open reading frame for dystrophin. Thus any dystrophin detected in this group of patients should consist of the severely truncated polypeptides that represent prematurely terminated translation products. Dystrophin was detected in blots from 17/29 biopsies and the observed sizes of the polypeptides were compared with predicted sizes calculated in two ways: if translation was terminated at the stop codon generated by each frameshifting deletion, and if the reading frame was restored and translation proceeded. In every case the observed size matched the size predicted on the basis of a restored reading frame. This was in accord with immunocytochemical labelling of scattered dystrophin positive fibres which were found on serial sections labelled with antibodies to both the rod and C-terminal domains. Thus analysis at the protein level supports genetic evidence of exon skipping as a mechanism which restores frameshifting mutations in some fibres.

(f Med Genet 1992;29:892-96)
\end{abstract}

Dystrophin is the protein product of the $\mathrm{Xp} 21$ gene which is defective in Duchenne and Becker muscular dystrophy (DMD, BMD). ${ }^{1}$ Initial studies on Western blots of muscle labelled with polyclonal antibodies indicated that dystrophin was absent or undetectable in patients with severe $\mathrm{DMD}$, and present with reduced size or abundance or both in patients with the milder condition, BMD. ${ }^{2}$ Genetic analysis shows that about $65 \%$ of patients have intragenic deletions or duplications, but there does not seem to be a simple correlation between clinical condition (DMD $v$ BMD) and either the size or position of the gene mutation. ${ }^{3-7}$

A proposal was made, however, that the exact position of the deletion breakpoints could affect protein synthesis and clinical expression by either disrupting or maintaining the open reading frame of triplet nucleotide codons which determine the amino acid sequence. ${ }^{8}$ This 'frameshift hypothesis' predicted that Becker patients would produce a semifunctional protein of smaller size (molecular weight) than normal, whereas Duchenne patients would exhibit no protein at all, owing to rapid degradation of a severely truncated protein which could only be synthesised up to the approximate position of the gene mutation before the frameshift generated a premature stop codon..$^{-11}$ The prediction that DMD patients have deletions which cause a frameshift and BMD patients have deletions which keep the reading frame intact has proved to be correct in over $90 \%$ of the cases examined, ${ }^{4512}$ although certain exceptions (particularly involving BMD patients with the frameshifting deletion of exons 3 to 7) have been noted. ${ }^{13}$

To date we have analysed dystrophin in muscle from over $130 \mathrm{DMD}$ patients and have found limited labelling in 55 to $60 \% .^{14-16}$ Correctly localised labelling at the periphery of muscle fibres in sections (generally on less than $1 \%$ of the fibre population but very occasionally on up to $25 \%$ ) was detected. Parallel labelling on blots consisted of faint bands which corresponded to full size or near full size molecules (that is, within the size range found in BMD patients) and not with the truncated molecules expected if translation was only allowed up to the position of an 'out of frame' deletion. ${ }^{15}$ At the time of our first reports the genetic status of many of the patients was unknown. Now DNA deletion analysis has been completed on a large number of patients and we report on one aspect of the gene and protein analysis in a group of patients known to have mutations which should disrupt the open reading frame.

\section{Materials and methods}

PATIENTS

All the patients were examined at the Regional Neurosciences Centre of Newcastle General Hospital over the last 20 years. For comparative purposes only, patients were differentiated as $\mathrm{DMD}$, intermediate $\mathrm{D} / \mathrm{BMD}$, or $\mathrm{BMD}$ on the basis of disease progression and the age at which independent mobility was lost (DMD before 12 years, D/BMD between 12 and 16 years, BMD after 16 years). Muscle biopsies were performed as part of the diagnostic procedure and stored in a liquid nitrogen archive.

\section{GENETIC ANALYSIS}

DNA isolated from lymphocytes was digested with the restriction enzyme HindIII, blotted, and analysed with $\mathrm{CDNA}$ probes ${ }^{17}$ as described by den Dunnen et al. ${ }^{5}$ The effect of deletion/ duplication endpoints on the open reading

Received 29 January 1992. 
frame was determined using the data on exon border types $(1,2$, or 3 according to the codon position) provided by Koenig et al. ${ }^{4}$ The predicted size of dystrophin for each patient was estimated in two ways: (A) the size expected if translation was prematurely terminated at the stop codon generated by each frameshifting deletion (estimated molecular weight of amino acids up to breakpoint plus those up to the stop codon after the deletion). This corresponds to synthesis of a truncated protein; (B) the size expected if the reading frame could be restored in the codon immediately following the deletion (estimated molecular weight of the total number of amino acids minus those in deleted exons). This corresponds to the production of an internally deleted or 'Becker-like' protein.

\section{PROTEIN ANALYSIS}

The two monoclonal antibodies (MAbs) used in this study (Dy4/6D3: rod domain, Dy8/6C5: C-terminus) are specific for dystrophin ${ }^{1618}$ and do not show any reactivity with muscle from patients who have a deletion in the Xp21 gene which removes the amino acids which form the antibody binding site. ${ }^{1920}$ The C-terminal antibody has been used as a control for true Xp21 encoded dystrophin in studies of the 'dystrophin related protein' ${ }^{21}{ }^{22}$ Immunocytochemical labelling and Western blotting analysis of dystrophin size and abundance were performed as described previously. ${ }^{1516}$ Dystrophin abundance was estimated from densitometric analysis of the dystrophin band on blots and the myosin heavy chain band on gels. ${ }^{1516}$ The observed size of dystrophin was estimated by comparing the migration distance of the uppermost band in each sample lane (corresponding to the polypeptide with the largest molecular weight) with the migration distance of the uppermost dystrophin band in normal control muscle run on the same blot. The size of the dystrophin polypeptide in each sample lane was expressed as a percentage of normal and the normal size (that is, $100 \%$ ) was taken to be $427 \mathrm{~K}$. Thus a dystrophin band of
$92 \%$ normal size would be assigned a molecular weight of $390 \mathrm{~K}(427 \times 0.92=393$, or 390 to the nearest $10 \mathrm{~K}$ ).

\section{STATISTICAL ANALYSIS}

Advice on the statistical comparison of predicted and observed dystrophin sizes was provided by $\mathrm{Mr}$ T Butler in the Department of Medical Statistics, University of Newcastle upon Tyne.

\section{Results}

Of 85 unrelated male patients with Duchenne and Becker muscular dystrophy who were considered old enough to be classified definitively, 29 (26 DMD and three intermediate D/BMD) were found to have mutations which disrupted the open reading frame. Of these, $17(14 \mathrm{DMD}$, three D/BMD) had detectable dystrophin on blots labelled with the rod MAb Dy4/6D3 which permitted the size of the protein to be estimated (table). All showed immunocytochemical (ICC) labelling on sections with both rod and C-terminus MAbs which varied from faint labelling on a few fibres $( \pm)$, and clear labelling on $<1 \%$ of fibres $(+)$, to a pattern which included weak labelling on a higher proportion (up to $25 \%$ ) of fibres with a few clearly labelled fibres $(t+)$. Five biopsies (four DMD, one D/BMD) showed labelling with the C-terminus MAb, Dy8/6C5, on blots and in these cases the size of dystrophin detected was the same when estimated with either MAb. Fig 1 shows dystrophin labelling of blot lanes and fig 2 shows labelling on the corresponding tissue sections from three DMD patients. In some biopsies (see lanes 2 and 10 in fig 1) additional bands corresponding to polypeptides of lower molecular weight were detected on blots labelled with the rod domain MAb. A Bland and Altman plot ${ }^{23}$ of the predicted and observed sizes is shown in fig 3. The horizontal line is placed at zero difference between predicted and observed

Summary of genetic and protein analyses in 17 patients with 'out of frame' gene mutations.

\begin{tabular}{|c|c|c|c|c|c|c|c|}
\hline Patient & $\begin{array}{l}\text { Age (y) at loss } \\
\text { of mobility }\end{array}$ & $\begin{array}{l}\text { Exons deleted } \\
\text { (or duplicated) }\end{array}$ & $\begin{array}{l}\text { Predicted size } \\
\mathrm{A}(\mathrm{K})\end{array}$ & $\begin{array}{c}\text { Predicted size } \\
\mathbf{B}(\mathrm{K})\end{array}$ & $\begin{array}{c}\text { Observed size } \\
(\mathrm{K}) \\
\text { (to nearest } \\
10 \mathrm{~K} \text { ) }\end{array}$ & $\begin{array}{l}\text { Dystrophin } \\
\text { abundance } \\
\text { (rod/C-term) }\end{array}$ & ICC \\
\hline $\begin{array}{l}\text { DMD 1 } \\
\text { DMD 2 } \\
\text { DMD 3 } \\
\text { DMD 4 } \\
\text { DMD 5 } \\
\text { DMD 6 } \\
\text { DMD 7 } \\
\text { DMD 8 } \\
\text { DMD 9 } \\
\text { DMD 10 } \\
\text { DMD 11 } \\
\text { DMD 12 } \\
\text { DMD 13 } \\
\text { DMD 14 } \\
\text { D/BMD 15 } \\
\text { D/BMD 16 } \\
\text { D/BMD } 17\end{array}$ & $\begin{array}{l}11 \cdot 9 \\
9 \cdot 1 \\
10 \\
11 \\
11 \cdot 2 \\
10 \cdot 4 \\
\mathrm{NY} \\
8 \cdot 7 \\
11 \cdot 6 \\
7 \cdot 2 \\
9 \cdot 3 \\
8 \cdot 8 \\
11 \cdot 9 \\
9 \cdot 6 \\
\mathrm{NY} \\
\mathrm{NY} \\
13.9\end{array}$ & $\begin{array}{c}8-16 \text { (dup) } \\
44 \\
44 \\
44 \\
44 \\
44 \\
45 \\
45 \\
45 \\
48-50 \\
48-50 \\
51 \\
51-55 \\
51-60 \\
3-7 \\
3-7 \\
44\end{array}$ & $\begin{array}{r}80 \\
245 \\
245 \\
245 \\
245 \\
245 \\
251 \\
251 \\
251 \\
268 \\
268 \\
286 \\
283 \\
284 \\
5 \\
5 \\
253\end{array}$ & $\begin{array}{l}433 \\
421 \\
421 \\
421 \\
421 \\
421 \\
420 \\
420 \\
420 \\
414 \\
414 \\
418 \\
392 \\
379 \\
406 \\
406 \\
421\end{array}$ & $\begin{array}{l}420 \\
420 \\
400 \\
410 \\
390 \\
410 \\
410 \\
410 \\
410 \\
410 \\
410 \\
420 \\
380 \\
360 \\
400 \\
400 \\
410\end{array}$ & $\begin{array}{c}5 / 0 \\
6 / 0 \\
30 / 6 \\
17 / 0 \\
20 / \mathrm{ND} \\
16 / 0 \\
26 / 0 \\
21 / 8 \\
3 / 0 \\
5 / 0 \\
4 / 0 \\
20 / 5 \\
25 / 3 \\
22 / \mathrm{ND} \\
28 / 0 \\
31 / 8 \\
25 / 0\end{array}$ & $\begin{array}{r}+ \\
+ \\
+ \\
+ \\
+ \\
+ \\
+ \\
+ \\
+ \\
+ \\
+ \\
+ \\
+ \\
+ \\
+ \\
+ \\
+ \\
+\end{array}$ \\
\hline
\end{tabular}

Estimates for predicted sizes (to nearest $1 \mathrm{~K}$ ) are (A) up to premature stop codon generated by frameshift, and (B) as though the reading frame was restored and synthesis continued. 


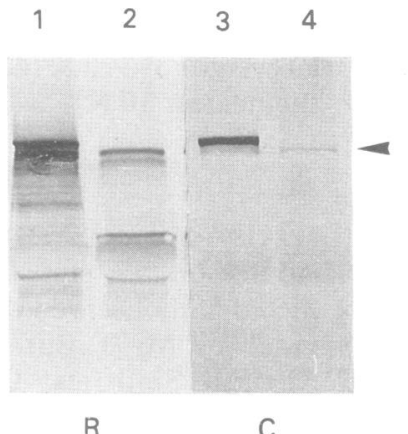

$R$

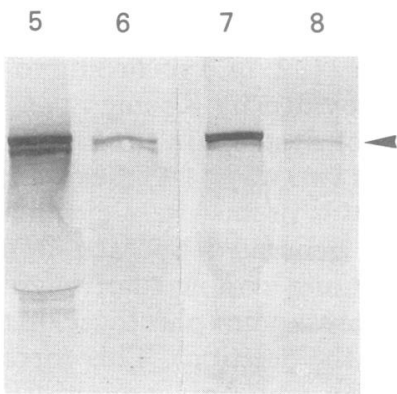

$R$

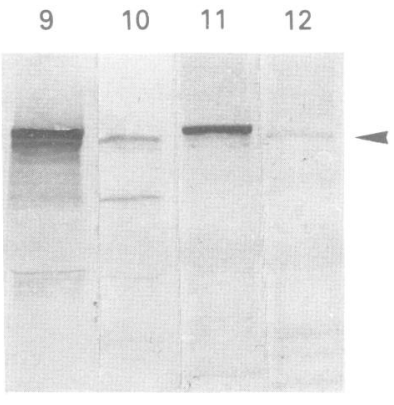

R

$\mathrm{C}$

Figure 1 Western blot lanes probed with monoclonal antibodies to the rod domain $(R)$ and $C$-terminus $(C)$ of dystrophin. Odd numbered lanes are normal control muscle, even numbered lanes are from patients: lanes 2 and $4=D M D 3$, lanes 6 and $8=D M D 8$, and lanes 10 and 12=DMD 12. Arrow heads mark dystrophin bands labelled with the C-terminus antibody.
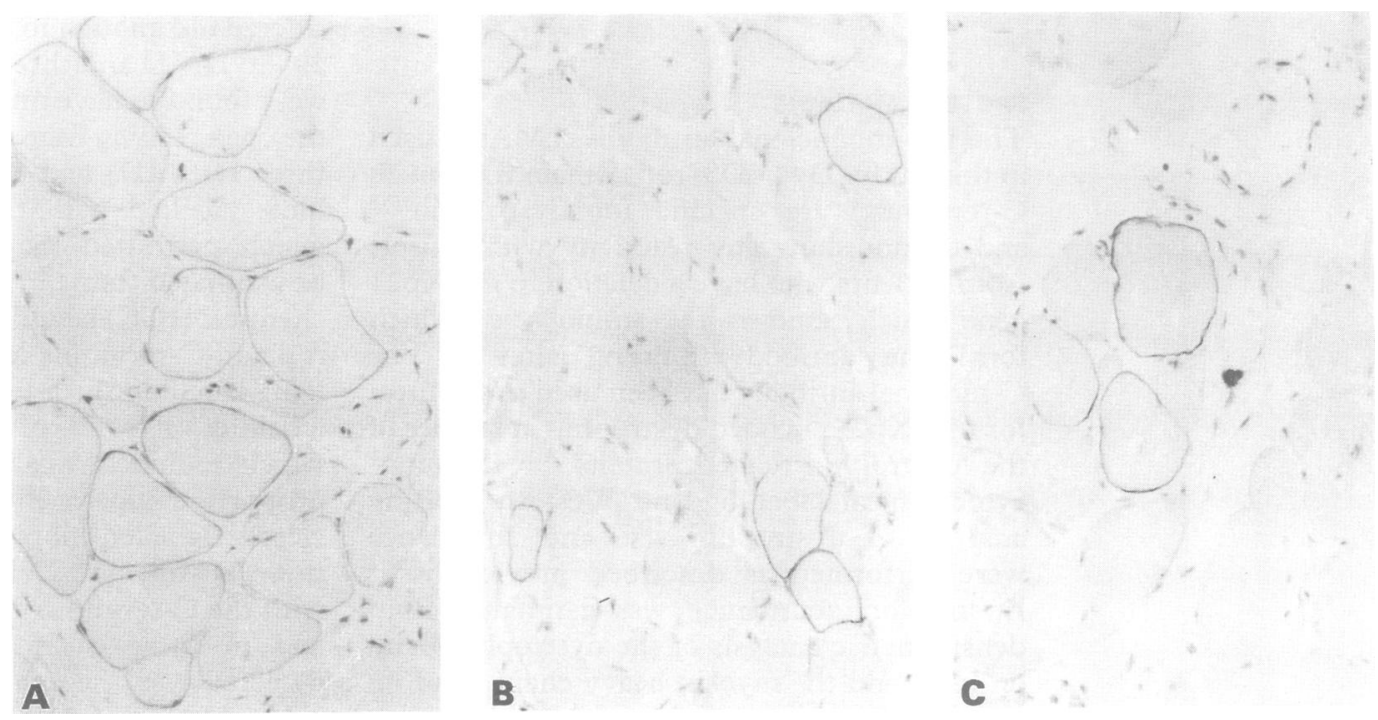

Figure 2 Tissue sections from the DMD muscle samples shown in fig 1 labelled with the antibody to the $C$-terminus of dystrophin. The areas chosen illustrate dystrophin positive fibres. Panel $A=D M D 3, B=D M D 8, C=D M D 12$. (Indirect peroxidase labelling.)

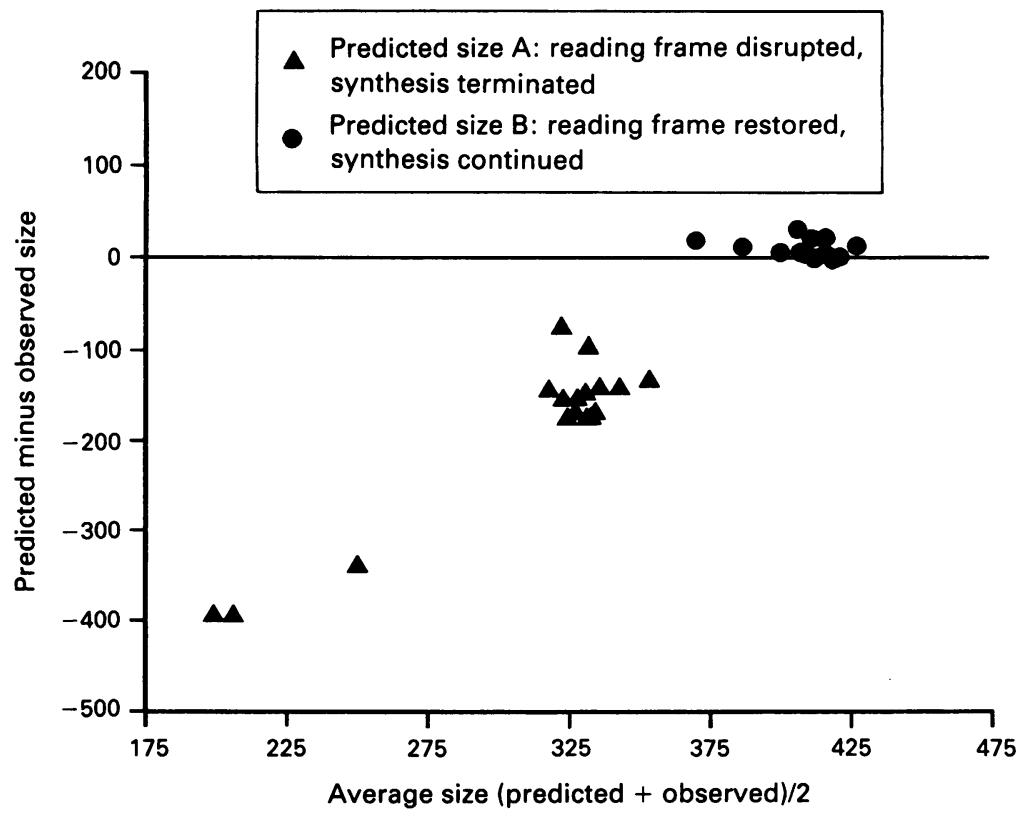

Figure 3 Bland and Altman plot of predicted and observed dystrophin sizes. sizes. Very clearly, all predicted sizes estimated by method A (synthesis up to the position of the premature stop codon) are very much smaller than the actual size observed. In contrast, all predicted sizes based on method B (restoration of the reading frame) are very close to the line of zero difference. All the observed sizes are slightly smaller than predicted size B (as indicated by a small positive difference between the two), but it is uncertain whether this reflects a systematic error in estimating the observed size from blots or a genuine small reduction in the size of the dystrophin protein present.

\section{Discussion}

This report shows that the size of dystrophin detected at greatly reduced levels in muscle from a group of DMD patients with 'out of frame' mutations corresponds to polypeptides translated from mRNA in which the reading frame has been restored. The fact that low levels of labelling have been found in serial tissue sections labelled with amino-terminal/ rod and C-terminal antibodies from different sources $^{162425}$ supports the view that a small 
percentage of DMD muscle fibres contain dystrophin with a C-terminus which can only be translated from transcripts with restored reading frame. ${ }^{26}$ This is the first report to describe C-terminal labelling of dystrophin on blots of DMD muscle, consistent with the evidence from tissue sections labelled with the same antibody. Previous studies ${ }^{27} 28$ have failed to detect any near full size material on blots. This may be because of the lability of the C-terminus, however, since we have found that the ' $\mathrm{C}$ terminal abundance' of dystrophin appears substantially lower than the 'rod abundance' in all BMD and DMD biopsies. ${ }^{16}$

From the table it appears that dystrophin labelling on blots and sections is particularly common in patients with a deletion of the single exon 44 or exon 45 . Recent studies on lymphocyte mRNA ${ }^{29}$ (G Galluzzi, personal communication) have shown that deletion of exon 45 may be extended to include loss of exon 44 (which would restore the reading frame), but these studies did not include analysis of protein expression in muscle. Our results provide evidence at the protein level to support an exon skipping mechanism ${ }^{29-31}$ which restores the reading frame so that low levels of an internally deleted 'Becker-like' protein are synthesised in some DMD fibres. In this study the observed size was slightly smaller than would be expected if the reading frame was restored with the codon immediately following the mutation. This would fit with the skipping of a whole exon but it is very difficult to assess accurately the band migration distances on blots from low percentage polyacrylamide gels, as these are easily distorted when the Western blot cassettes are assembled.

In principle, translation of dystrophin in the majority of DMD muscle fibres (or alternatively, for most of the dystrophin in each fibre) should cease at the frameshifting mutation so that the major protein species present should be truncated. In practice, however, we found that although some lower molecular weight bands were observed in a few cases (which might represent truncated translation products), the major gene products detected were the 'Becker-like' dystrophin molecules of near normal size. This could be the result of increased stability at the level of transcript or protein. Several reports have shown decreased amounts of dystrophin mRNA in DMD muscle even after correction for muscle content. ${ }^{3032}$ However, an mRNA which is translated throughout may be more stable than one from which protein synthesis is prematurely terminated. This may influence the relative abundance of mRNA in favour of an exon skipping product. Alternatively (or additionally), the presence of the C-terminus in the internally deleted 'Becker-like' dystrophin molecules may selectively enhance their stability and survival, thus causing an enrichment of this form over the truncated form.

Could the very low levels of dystrophin synthesis in DMD muscle have any functional significance? The mean age for loss of independent walking in our entire DMD population is 9.02 years, yet in this small group of patients, as in a larger cohort under review (manuscript in preparation), subjects with detectable dystrophin are more likely to become wheelchair bound from 9 to 12 years than from 6 to 9 years (table). This is a marginal difference with individual exceptions, yet it suggests that even a small amount of dystrophin is better than none at all.

The technical expertise of Keith Davison, Martin Barron, Daisy Haggerty, and Marleen van Paassen is gratefully acknowledged, as is the financial support of the Muscular Dystrophy Group of Great Britain, the Wellcome Trust, the Medical Research Council, the Princess Beatrix Fund, the Dutch Prevention Fund, and the Netherlands Foundation of Medical Research (MEDIGON).

1 Hoffman EP, Brown RH, Kunkel LM. Dystrophin: the protein product of the Duchenne muscular dystrophy $87 ; 51: 919-28$

2 Hoffman EP, Fischbeck KH, Brown RH, et al. Characterization of dystrophin in muscle-biopsy specimens from patients with Duchenne's or Becker's muscular dystrophy. $N$ Engl f Med 1988;318:1363-8.

3 Davies KE, Smith TJ, Bundey S, et al. Mild and severe muscular dystrophy associated with deletions in Xp21 of the human X chromosome. I Med Genet 1988;25:9-13.

4 Koenig M, Beggs AH, Moyer M, et al. The molecular basis for Duchenne versus Becker muscular dystrophy: correlation of severity with type of deletion. Am $\mathcal{J}$ Hum Genet 1989;45:498-506.

5 Den Dunnen JT, Grootscholten PM, Bakker E, et al. Topography of the Duchenne muscular dystrophy (DMD) gene: FIGE and CDNA analysis of 194 cases reveals 115 deletions

6 Baumbach LL, Chamberlain JS, Ward PA, Farwell NJ, Caskey CT. Molecular and clinical correlations of deletions leading to Duchenne and Becker muscular dystrophies. Neurology 1989;39:465-74.

7 Hodgson S, Hart K, Abbs S, et al. Correlation of clinical and deletion data in Duchenne and Becker muscular dystrophy. F Med Genet 1989;26:682-93.

8 Monaco AP, Bertelson CJ, Liechti-Gallati S, Moser H, Kunkel LM. An explanation for the phenotypic differences between patients bearing partial deletions of the DMD locus. Genomics 1988;2:90-5.

9 Hoffman EP, Kunkel LM. Dystrophin abnormalities in Duchenne/Becker muscular dystrophy. Neuron 1989; 2:1019-29.

10 Bulman DE, Gangopadhyay SB, Bebchuck KG, Worton RG, Ray PN. Point mutation in the human dystrophin gene: identification through Western blot analysis. Genomics 1991;10:457-60.

11 Roberts RG, Bobrow M, Bentley DR. Point mutations in the dystrophin gene. Proc Natl Acad Sci USA 1992; 89:2331-5.

12 Gillard EF, Chamberlain JS, Murphy EG, et al. Molecular and phenotypic analysis of patients with deletions within the deletion-rich region of the Duchenne muscular dystrophy (DMD) gene. Am f Hum Genet 1989;45:507-20.

13 Malhotra SB, Hart KA, Klamut HJ, et al. Frame-shift deletions in patients with Duchenne and Becker muscular dystrophy. Science 1988;242:755-9.

14 Nicholson LVB, Davison K, Johnson MA, et al. Dystrophin in skeletal muscle. II. Immunoreactivity in patients with Xp21 muscular dysirophy. $\mathcal{F}$ Neurol Sci 1989;

5 Nicholson LVB, Johnson MA, Gardner-Medwin D, Bhattacharya $S$, Harris JB. Heterogeneity of dystrophin expression in patients with Duchenne and Becker muscular dystrophy. Acta Neuropathol (Berl) 1990;80:239-50.

16 Nicholson LVB, Johnson MA, Davison K, et al. Dystrophin or a 'related protein' in Duchenne muscular dystrophy? Acta Neurol Scand 1992;86:8-14.

17 Koenig M, Hoffman EP, Bertelson CJ, Monaco AP, Feener CA, Kunkel LM. Complete cloning of the Duchenne muscular dystrophy (DMD) CDNA and preliminary genomic organization of the DMD gene in normal and affected individuals. Cell 1987;50:509-17.

18 Nicholson LVB, Davison K, Falkous G, et al. Dystrophin in skeletal muscle. I. Western blot analysis using a monoclonal antibody. $f$ Neurol Sci 1989;94:125-36.

19 England S, Nicholson LVB, Johnson MA, et al. Very mild muscular dystrophy associated with the deletion of $46 \%$ of dystrophin. Nature 1990;343:180-2.

20 Récan D, Chafey P, Leturcq F, et al. Are cysteine-rich and C-terminal domains of dystrophin critical for sarcolemmal localization? f Clin Invest 1992;89:712-6.

21 Pons F, Augier N, Léger JOC, et al. A homologue of dystrophin is expressed at the neuromuscular junctions of mdx mice: immunological evidence. FEBS Lett 1991; $m d x$ mice:
282:161-5. 
22 Augier N, Boucraut J, Léger J, et al. A homologue of dystrophin is expressed at the blood vessel membrane of DMD and BMD patients: immunological evidence. $f$ Neurol Sci 1992;107:233-8.

23 Bland JM, Altman DG. Statistical method for assessing agreement between two methods of clinical measurement. Lancet $1991 ; \mathrm{i}: 307-10$.

24 Vainzof M, Zubrzycka-Gaarn EE, Rapaport D, et al. Immunofluorescence dystrophin study in Duchenne dystrophy through the concomitant use of two antibodies directed against the carboxy-terminal and the aminoterminal region of the protein. F Neurol Sci 1991;101:1417.

25 Voit T, Stuettgen P, Cremer M, Goebel HH. Dystrophin as a diagnostic marker in Duchenne and Becker muscular dystrophy. Correlation of immunofluorescence and Western blot. Neuropediatrics 1991;22:152-62.

26 Hoffman EP, Morgan JE, Watkins SC, Partridge TA. Somatic reversion/suppression of the mouse $m d x$ phenotype in vivo. F Neurol Sci 1990;99:9-25.

27 Arahata K, Hoffman EP, Kunkel LM, et al. Dystrophin diagnosis: comparison of dystrophin abnormalities by immunofluorescence and immunoblot analyses. Proc Natl Acad Sci USA 1989;86:7154-8.

28 Bulman DE, Murphy EG, Zubrzycka-Gaarn EE, Worton RG, Ray PN. Differentiation of Duchenne and Becker muscular dystrophy phenotypes with amino- and carboxy-terminal antisera specific for dystrophin. Am $\mathcal{f}$ Hum Genet 1991;48:295-304.

29 Roberts RG, Barby TFM, Manners E, Bobrow M, Bentley DR. Direct detection of dystrophin gene rearrangements by analysis of dystrophin mRNA in peripheral blood by analysis of dystrophin mRNA in peripheral

30 Chelly J, Gilgenkrantz $\mathrm{H}$, Lambert $M$, et al. Effect of dystrophin gene deletions on mRNA levels and processing in Duchenne and Becker muscular dystrophies. Cell 1990;63:1239-48.

31 Matsuo M, Masumura T, Nishio H, Nakajima T, Kitoh Y. Exon skipping during splicing of dystrophin mRNA precursor due to an intraexon deletion in the dystrophin gene of Duchenne muscular dystrophy Kobe. 7 Clin Invest 1991;87:2127-31.

32 Oronzi Scott M, Sylvester JE, Heiman-Patterson T, et al. Duchenne muscular dystrophy gene expression in normal and diseased human muscle. Science 1988;239:1418-20. 